\title{
A Comparison of the Thompson Encephalopathy Score and Amplitude-Integrated Electroencephalography in Infants with Perinatal Asphyxia and Therapeutic Hypothermia
}

\author{
Lauren C. Weeke ${ }^{a, b}$ Ana Vilan ${ }^{c}$ Mona C. Toet ${ }^{a, b}$ Ingrid C. van Haastert ${ }^{a, b}$ \\ Linda S. de Vries ${ }^{a}$ b Floris Groenendaala, b \\ ${ }^{a}$ Department of Neonatology, Wilhelmina Children's Hospital, and b Brain Center Rudolf Magnus, University Medical \\ Center Utrecht, Utrecht, The Netherlands; ' Department of Neonatology, Hospital São João, Porto, Portugal
}

\section{Keywords \\ Perinatal asphyxia - Therapeutic hypothermia . \\ Encephalopathy - Thompson score . \\ Electroencephalography $\cdot$ Neurodevelopment}

\begin{abstract}
Background: In previous studies clinical signs or amplitudeintegrated electroencephalography (aEEG)-based signs of encephalopathy were used to select infants with perinatal asphyxia for treatment with hypothermia. Aim: The objective of this study was to compare Thompson encephalopathy scores and aEEG, and relate both to outcome. Subjects and Methods: Thompson scores, aEEG, and outcome were compared in 122 infants with perinatal asphyxia and therapeutic hypothermia. Of these 122 infants, 41 died and 7 had an adverse neurodevelopmental outcome. A receiver operating characteristics (ROC) analysis was also performed. $\boldsymbol{R e}$ sults: Thompson scores were higher in infants with more abnormal aEEG background patterns (ANOVA, $p<0.001$ ). The ROC analysis demonstrated that a Thompson score of 11 or higher or an aEEG background pattern of continuous low
\end{abstract}

\begin{tabular}{ll}
\hline KARGER & $\begin{array}{l}\text { (c) 2017 The Author(s) } \\
\text { Published by S. Karger AG, Basel }\end{array}$ \\
E-Mail karger@karger.com & Karger \\
www.karger.com/neo & $\begin{array}{l}\text { This article is licensed under the Creative Commons Attribution- } \\
\text { NonCommercial-NoDerivatives 4.0 International License (CC BY- } \\
\text { NC-ND) (http://www.karger.com/Services/OpenAccessLicense). } \\
\text { Usage and distribution for commercial purposes as well as any dis- } \\
\text { tribution of modified material requires written permission. }\end{array}$
\end{tabular}

voltage or worse was associated with an adverse outcome (AUC 0.84 for both). Conclusions: High Thompson scores and a suppressed aEEG background pattern are associated with an adverse outcome after perinatal asphyxia and therapeutic hypothermia. Further studies are needed to identify the best technique with which to select patients for therapeutic hypothermia

(C) 2017 The Author(s) Published by S. Karger AG, Basel

\section{Introduction}

An intrapartum hypoxic-ischemic event resulting in brain injury is a common cause of neonatal hypoxic-ischemic encephalopathy (HIE) [1]. An estimate of the incidence of HIE in developed countries is 1.5 per 1,000 term live births, with a higher incidence in low-resource settings, with estimates ranging from 2.3 to 26.5 per 1,000 live births $[2,3]$.

Adverse outcomes are rare in infants with mild HIE, while those with moderate to severe HIE will invariably develop a major disability or die $[4,5]$. Besides cerebral 
palsy, major disability includes cognitive and developmental problems [6, 7].

There is now sufficient data to conclude that hypothermia commencing by age $6 \mathrm{~h}$ is neuroprotective and is considered the standard of care for term infants who meet the trial entry criteria for therapeutic cooling [8]. This means that early identification of newborns at risk for HIE in referral centers is crucial.

The amplitude-integrated electroencephalography (aEEG) pattern obtained within $6 \mathrm{~h}$ after birth in term asphyxiated infants has been shown to be useful for predicting neurodevelopmental outcome and was used in clinical trials to select infants for cooling [9-11]. Both positive and negative predictive values, PPV and NPV, have been assessed at 3 and $6 \mathrm{~h}[12,13]$, and were shown to be high in normothermic infants. Although the predictive value has changed in the era of hypothermia, the aEEG is still useful for selecting infants who will benefit from hypothermia [14]. Although it is easy to execute, bedside monitoring with aEEG is not available in the majority of referral centers, even in developed countries, and may also be misleading due to artifacts [15].

Clinical assessment of HIE based on a Thompson score of more than 7 is also used as an entry criterion for cooling [16]. The Thompson score is a numeric scoring system that requires no equipment and no specific training with a high predictive value for outcome [17]. Recently, Thompson scores were analyzed during or just before the start of hypothermia [18-20]. The primary aim of the present study was to compare Thompson scores and aEEG patterns in infants selected for therapeutic hypothermia, and relate these findings to outcome at 2 years of age.

\section{Methods}

The ethics committee of the University Medical Center Utrecht waived the requirement to obtain informed consent for this retrospective study with anonymized data. From January 2008 to September 2014, 169 neonates with a gestational age of at least 36 weeks and clinical signs of perinatal asphyxia were treated with moderate hypothermia. All infants were admitted to the level III neonatal intensive care unit (NICU) of the Wilhelmina Children's Hospital, Utrecht, The Netherlands.

Of the 169 infants, 134 without congenital malformations or syndromes, or need for extracorporeal membrane oxygenation, had aEEG and Thompson scores on admission and were available for retrospective analysis. Forty-one infants died while 81 survived and had a follow-up of at least 24 months, and these 122 were selected for the present study. Perinatal asphyxia was defined as described previously [16]. The decision to start therapeutic hypothermia was based on either a Thompson score $>7$ within $6 \mathrm{~h}$ after

Table 1. Clinical data of the patients

Gestational age, weeks
Birth weight, g
Male/female
Apgar $1 \mathrm{~min}$
Apgar 5 min
pH

$40.0(2.2)$

$3,500(858)$

$69 / 53$

$1(2)$

$3(4)$

$6.90(0.25)$

Lactate

$15.5(8.0)$

Sarnat score on admission

Grade $1 \quad 16$

Grade 2

Grade 3

Thompson score $>7$

aEEG BS or more severely depressed $\quad 83$

Died 41

Follow-up of 24 months or more $\quad 81$

Data are presented as $n$ or median (IQR).

birth, or the presence of a discontinuous normal voltage (DNV) pattern on the aEEG with a lower amplitude limit below $5 \mu \mathrm{V}$, or a more suppressed aEEG background pattern. aEEG patterns were analyzed as described previously, and scored as continuous normal voltage (CNV), DNV, burst-suppression (BS), continuous low voltage (CLV), or flat trace (FT) [16]. The data were retrieved from the medical files. Neurodevelopmental assessment was performed at regular intervals as described previously up to the age of 24 months [21]. Adverse outcomes were considered as death, cerebral palsy, severe hearing or visual impairments, or an adverse neurodevelopment (Griffiths developmental quotient <88; Bayley Scales of Infant and Toddler Development, third edition, BSID-III, cognitive composite score $<85$ ).

\section{Statistical Analysis}

Thompson scores and the aEEG pattern on admission were compared using analysis of variance (ANOVA) with a Bonferroni post hoc test. In addition, the association between aEEG patterns and Thompson scores on admission and outcome were analyzed using receiver operating characteristics (ROC). The area under the curve (AUC) with 95\% confidence intervals (CI) was calculated and the optimal cut-off values for predicting an adverse outcome were determined.

\section{Results}

\section{Clinical Data}

The clinical characteristics of the infants are given in Table 1. Of the 122 infants, 81 (66.4\%) survived and were seen at a follow-up age of at least 24 months. All deaths occurred after redirection of care. The decision to redirect care was based on information obtained with clinical assessment, aEEG, and imaging (cranial ultrasound and/or MRI) as described previously [22]. 


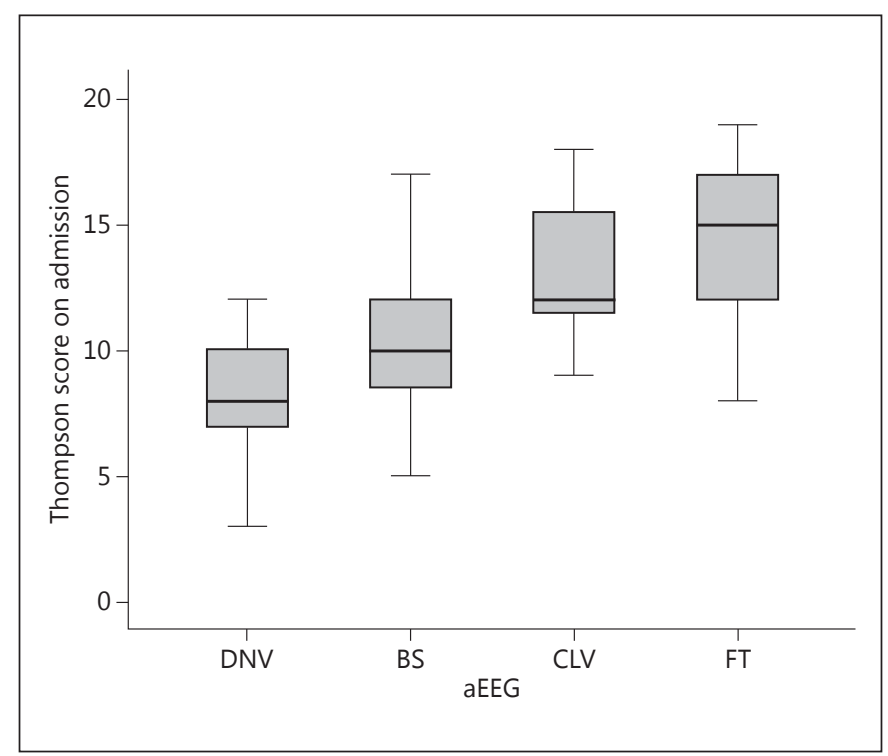

Fig. 1. Thompson score on admission plotted against aEEG on admission. One infant with a CNV pattern was added to the DNV data.

\section{Thompson Score versus aEEG}

Twenty infants had a Thompson score of 7 or lower, of which 13 had a DNV $(n=12)$ or CNV $(n=1)$. The other 7 had a BS pattern. Of the 102 infants with a Thompson score of more than 7 , a BS pattern or worse was seen in 76 .

Box plots of the Thompson score versus aEEG patterns are presented in Figure 1. A significant association between aEEG patterns and Thompson scores could be demonstrated (ANOVA, $p<0.001$ ). The post hoc analysis using Bonferroni correction showed significant differences in Thompson scores between DNV and BS, and between BS and CLV/FT patterns. The differences in Thompson scores between CLV and FT patterns were not significant.

\section{Thompson Score and aEEG versus Outcome}

The predictive values in Table $2 \mathrm{a}$ are presented based on previously published cut-off values $[12,17]$. The specificity and PPV of both cut-off values are low. Median Thompson scores were lowest in infants with a normal outcome and highest in infants who died (Table 2b). aEEG scores were most abnormal in infants who died (Table 2b).

Of the 2 infants with a Thompson score of 7 or lower and an adverse outcome, 1 had a score of 7 , and 1 a score of 4 within $2 \mathrm{~h}$ after birth. Both showed a rapid deterio- ration over the following hours. All 3 infants with a DNV pattern and an adverse outcome showed a rapid deterioration of the aEEG background pattern after admission.

\section{ROC Analysis of Thompson Score and aEEG}

Thompson scores and aEEG both showed an AUC of more than 0.80 . The difference between them was not significant (Table 3 ).

\section{Discussion}

The present study compared Thompson scores and aEEG before initiating therapeutic hypothermia in infants with perinatal asphyxia who qualified for treatment with moderate hypothermia. Our data demonstrate a strong association between the aEEG background pattern and Thompson score. Although the Thompson score contains many items on behavior, (a)EEG is not part of the score. Like in the Apgar score, the predictive value of the items has not been tested separately [23]. Therefore, we cannot say which items of the Thompson score were most valuable in relation to outcome.

The Thompson score and aEEG background pattern have a similar predictive value for an adverse outcome. However, the aEEG may have several advantages over the Thompson score. Firstly, the aEEG is a continuous measurement, and can identify (subclinical) seizures. Secondly, the aEEG can be sent out for a second opinion or expert revision. This is more difficult with the Thompson score, which needs to be captured on video for revision.

In our study, the Thompson score cut-off value to qualify for hypothermia was based on the original paper by Thompson et al. [17]. Infants with a score of more than 7 on the first day after birth had the higher risk of an adverse outcome. Horn et al. [19] analyzed different cut-off levels of the Thompson score in predicting an abnormal 6-h aEEG. At a level of $\geq 7$ the sensitivity was $100 \%$ and specificity $66.7 \%$, and at a level of $\geq 8$ the sensitivity was $94.4 \%$ and specificity $75.0 \%$. However, the Thompson score was measured when treatment with hypothermia had already commenced. Very high Thompson scores $(\geq 16)$ at age 3-5 $\mathrm{h}$ during hypothermia were followed by a severely abnormal aEEG or death at $48 \mathrm{~h}$ [18].

We confirmed that clinical assessment using the Thompson score before starting hypothermia is associated with outcome, since the highest scores were encountered in the infants who died. ROC analysis showed that 
Table 2. Thompson scores and aEEG versus outcome

\begin{tabular}{|c|c|c|c|c|}
\hline & Sensitivity & Specificity & PPV & NPV \\
\hline Thompson score $\leq 7$ versus $>7$ & 0.96 & 0.24 & 0.45 & 0.90 \\
\hline aEEG DNV versus BS, CLV, FT & 0.94 & 0.49 & 0.54 & 0.92 \\
\hline \multicolumn{5}{|c|}{ b Thompson scores and aEEG results versus outcome } \\
\hline Outcome & $\begin{array}{l}\text { Normal } \\
(n=74)\end{array}$ & $\begin{array}{l}\mathrm{CP} \text {, delayed } \\
\text { development }(n=7)\end{array}$ & Died $(n=41)$ & \\
\hline Median Thompson score & $9(3)$ & $10.5(4)$ & $15(6)$ & \\
\hline Thompson score $>7$ & 56 & 7 & 39 & \\
\hline Thompson score $\leq 7$ & 18 & 0 & 2 & \\
\hline \multicolumn{5}{|l|}{$\mathrm{aEEG}$} \\
\hline DNV & $36^{\mathrm{a}}$ & 0 & 3 & \\
\hline BS & 31 & 6 & 11 & \\
\hline CLV & 2 & 0 & 7 & \\
\hline FT & 5 & 1 & 20 & \\
\hline
\end{tabular}

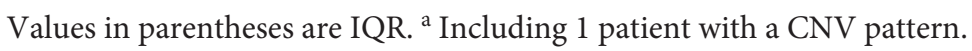

Table 3. ROC analysis of Thompson score and aEEG versus outcome

\begin{tabular}{lllll}
\hline & Cut-off value & AUC $(95 \%$ CI $)$ & Sensitivity & Specificity \\
\hline Thompson score & 11 & $0.84(0.75-0.91)$ & 0.76 & 0.83 \\
aEEG & CLV or worse & $0.84(0.76-0.91)$ & 0.60 & 0.93 \\
\hline
\end{tabular}

a score of 11 or more was the cut-off level for an adverse outcome. A recent study investigating infants in the Dutch PharmaCool trial showed a comparable cut-off level. A Thompson score of 12 or more was associated with death before discharge [20]. aEEG background patterns were not analyzed in that study.

In the past we and others have demonstrated that suppressed aEEG background patterns within the first $24 \mathrm{~h}$ were followed by an adverse outcome $[12,13]$. When therapeutic hypothermia is used, the predictive value of the aEEG is delayed until 24-36 h [14]. Furthermore, while a BS pattern during normothermia was associated with an adverse outcome, in the period of hypothermia CLV or FT patterns are most likely to be followed by an adverse outcome. Interestingly, the Thompson score and aEEG have a comparable area under the ROC curve of approximately 0.83 .

aEEG, Thompson Score, and Outcome
Both the Thompson score and aEEG obtained before starting hypothermia treatment had a lower specificity and PPV compared to previous studies in the period before hypothermia was used. Analysis with aEEG was slightly better than with the Thompson score. The lower specificity and PPV are attributed to the neuroprotective effects of hypothermia.

The present study does not answer the question of which of the 2 assessment systems, Thompson score or aEEG, is better in selecting neonates for treatment with hypothermia. It is unknown how many patients with either perinatal asphyxia and a low Thompson score or nonsuppressed aEEG did not receive hypothermia, but nevertheless subsequently developed neonatal encephalopathy with seizures. In our cohort we observed that the Thompson score was $\leq 7$ in 20 cases. If only the Thompson score had been used, these infants would not have 
been treated with hypothermia. Because of the aEEG findings, these cases were considered candidates for hypothermia. The Thompson score did not identify patients that were missed by aEEG in this study. This is in contrast with the findings of Sarkar et al. [24], but in agreement with our previous experience and that of others $[12,13]$.

A trial randomizing infants with asphyxia to the use of aEEG or the Thompson score might answer the question of which technique is superior in selecting infants with perinatal asphyxia for treatment with hypothermia. Until then, both techniques may be used to select infants with perinatal asphyxia for therapeutic hypothermia. With the cut-off levels obtained through ROC analysis presented in this study, the Thompson score and aEEG may be used to select infants who might benefit from additional neuroprotective strategies in addition to hypothermia.

\section{Conclusions}

Both high Thompson scores and a suppressed aEEG background pattern are associated with an adverse outcome after perinatal asphyxia and therapeutic hypothermia. Further studies are needed to identify the best technique with which to select patients for therapeutic hypothermia. The novel cut-off levels presented in the present study may be used to select patients for additional neuroprotective strategies.

\section{Acknowledgements}

The authors thank the nurses of the Neonatal Intensive Care Unit for their dedicated use of the aEEG.

\section{Disclosure Statement}

The authors declare no conflicts of interest.

\section{References}

1 Cowan F, Rutherford M, Groenendaal F, Eken P, Mercuri E, Bydder GM, Meiners LC, Dubowitz LMS, de Vries LS: Origin and timing of brain lesions in term infants with neonatal encephalopathy. Lancet 2003;361:736742.

2 Kurinczuk JJ, White-Koning M, Badawi N: Epidemiology of neonatal encephalopathy and hypoxic-ischaemic encephalopathy. Early Hum Dev 2010;86:329-338.

3 Lawn JE, Lee AC, Kinney M, Sibley L, Carlo WA, Paul VK, Pattinson R, Darmstadt GL: Two million intrapartum-related stillbirths and neonatal deaths: where, why, and what can be done? Int J Gynaecol Obstet 2009; 107(suppl 1):S5-S19.

4 de Vries LS, Jongmans MJ: Long-term outcome after neonatal hypoxic-ischaemic encephalopathy. Arch Dis Child Fetal Neonatal Ed 2010;95:F220-F224.

5 Pin TW, Eldridge B, Galea MP: A review of developmental outcomes of term infants with post-asphyxia neonatal encephalopathy. Eur J Paediatr Neurol 2009;13:224-234.

6 van Handel M, de Sonneville L, de Vries LS, Jongmans MJ, Swaab H: Specific memory impairment following neonatal encephalopathy in term-born children. Dev Neuropsychol 2012;37:30-50
7 Perez A, Ritter S, Brotschi B, Werner H, Caflisch J, Martin E, Latal B: Long-term neurodevelopmental outcome with hypoxicischemic encephalopathy. J Pediatr 2013;163: 454-459.

8 Jacobs SE, Berg M, Hunt R, Tarnow-Mordi WO, Inder TE, Davis PG: Cooling for newborns with hypoxic ischaemic encephalopathy. Cochrane Database Syst Rev 2013; 1:CD003311.

9 van Laerhoven $H$, de Haan TR, Offringa $M$, Post B, van der Lee JH: Prognostic tests in term neonates with hypoxic-ischemic encephalopathy: a systematic review. Pediatrics 2013;131:88-98.

10 Azzopardi DV, Strohm B, Edwards AD, Dyet L, Halliday HL, Juszczak E, Kapellou O, Levene $M$, Marlow N, Porter E, Thoresen $M$, Whitelaw A, Brocklehurst P: Moderate hypothermia to treat perinatal asphyxial encephalopathy. N Engl J Med 2009;361:13491358

11 Simbruner G, Mittal RA, Rohlmann F, Muche R: Systemic hypothermia after neonatal encephalopathy: outcomes of neo. nEURO.network RCT. Pediatrics 2010;126: e771-e778.

12 Toet MC, Hellstrom-Westas L, Groenendaal F, Eken P, de Vries LS: Amplitude integrated EEG at 3 and 6 hours after birth in fullterm neonates with hypoxic-ischaemic encephalopathy. Arch Dis Child Fetal Neonatal Ed 1999;81:F19-F23.
13 al Naqeeb N, Edwards AD, Cowan FM, Azzopardi D: Assessment of neonatal encephalopathy by amplitude-integrated electroencephalography. Pediatrics 1999;103:12631271.

14 Thoresen M, Hellstrom-Westas L, Liu X, de Vries LS: Effect of hypothermia on amplitude-integrated electroencephalogram in infants with asphyxia. Pediatrics 2010;126: e131-e139.

15 Toet MC, van Rooij LG, de Vries LS: The use of amplitude integrated electroencephalography for assessing neonatal neurologic injury. Clin Perinatol 2008;35:665-678.

16 Groenendaal F, Casaer A, Dijkman KP, Gavilanes AW, de Haan TR, Ter Horst HJ, Laroche S, Naulaers G, Rijken M, van Straaten HL, Steiner K, Swarte RM, Zecic A, Zonnenberg IA: Introduction of hypothermia for neonates with perinatal asphyxia in the Netherlands and Flanders. Neonatology 2013;104: 15-21.

17 Thompson CM, Puterman AS, Linley LL, Hann FM, van der Elst CW, Molteno CD, Malan AF: The value of a scoring system for hypoxic ischaemic encephalopathy in predicting neurodevelopmental outcome. Acta Paediatr 1997;86:757-761. 
18 Horn AR, Swingler GH, Myer L, Linley LL, Chandrasekaran M, Robertson NJ: Early clinical predictors of a severely abnormal amplitude-integrated electroencephalogram at 48 hours in cooled neonates. Acta Paediatr 2013; 102:e378-e384.

19 Horn AR, Swingler GH, Myer L, Linley LL, Raban MS, Joolay Y, Harrison MC, Chandrasekaran M, Rhoda NR, Robertson NJ: Early clinical signs in neonates with hypoxic ischemic encephalopathy predict an abnormal amplitude-integrated electroencephalogram at age 6 hours. BMC Pediatr 2013;13:52.
20 Thorsen P, Jansen-van der Weide MC, Groenendaal F, Onland W, van Straaten HL, Zonnenberg I, Vermeulen JR, Dijk PH, Dudink J, Rijken M, van Heijst A, Dijkman KP, Cools F, Zecic A, van Kaam AH, de Haan TR: The Thompson encephalopathy score and short-term outcomes in asphyxiated newborns treated with therapeutic hypothermia. Pediatr Neurol 2016;60:49-53.

21 Alderliesten T, de Vries LS, Benders MJ, Koopman C, Groenendaal F: MR imaging and outcome of term neonates with perinatal asphyxia: value of diffusion-weighted MR imaging and ${ }^{1} \mathrm{H}$ MR spectroscopy. Radiology 2011;261:235-242.
22 Bonifacio SL, deVries LS, Groenendaal F: Impact of hypothermia on predictors of poor outcome: how do we decide to redirect care? Semin Fetal Neonatal Med 2015;20:122-127.

23 D'Souza SW, Black P, Cadman J, Richards B: Umbilical venous blood $\mathrm{pH}$ : a useful aid in the diagnosis of asphyxia at birth. Arch Dis Child 1983;58:15-19.

24 Sarkar S, Barks JD, Donn SM: Should amplitude-integrated electroencephalography be used to identify infants suitable for hypothermic neuroprotection? J Perinatol 2008;28: $117-122$. 